\title{
Quantitative genetic variation of esterase activity associated with a gene amplification in Culex quinquefasciatus
}

\author{
JAMES A. FERRARI \& GEORGE P. GEORGHIOU* \\ Department of Biology, California State University, San Bernadino, CA 92407, USA and *Department of Entomology, \\ University of California, Riverside, CA 92521, USA
}

\begin{abstract}
Amplification of the esterase B1 gene is responsible for insecticide resistance in the mosquito Culex quinquefasciatus. We used a mating scheme to isolate chromosomes carrying amplified esterase genes from a long-selected laboratory strain (Tem-R) to determine whether observed variation in esterase activity had a genetic basis. The amplified esterase genes segregated as a block and a possible newly arisen esterase B1 copy-number variant was found among the progeny of females which carried amplified B1 genes on only one homologue. A quantitative genetic analysis found significant genetic variation of esterase activity among families which carried different amplification-bearing chromosomes from the Tem- $\mathrm{R}$ strain. Esterase B1 copy-number variation among these Tem-R chromosomes is the most likely basis for the observed genetic variation in esterase activity.
\end{abstract}

Keywords: Culex quinquefasciatus, esterase activity, gene amplification, insecticide resistance.

\section{Introduction}

Quantitative genetic variation affecting activity has been detected for a number of enzymes in populations of Drosophila melanogaster (Laurie-Ahlberg et al., $1980,1982)$. Activity variation is usually partitioned into that due to allelic differences at the enzyme locus (i.e. allozymic variation) and that due to modifier genes. When a gene coding an enzyme is amplified, existing in multiple copies in the genome, variation in the number of copies carried by individuals can be an additional source of variation in activity.

Gene amplification has commonly been observed in cell lines and organisms exposed to toxic substances. As amplification of the dihydrofolate-reductase gene was found to be a mechanism of resistance to anticancer drugs in cultured tumour cells, gene amplification has been observed in mammalian cell lines exposed to a variety of selecting agents (see Schimke, 1982, 1986; Stark \& Wahl, 1984). Copper resistance in yeast (Fogel \& Welch, 1982; Fogel et al., 1983) and heavy-metal tolerance in Drosophila melanogaster (Maroni et al., 1987) are due to copy-number increases in metallothionine genes. Amplification of esterase

Correspondence: Dr James A. Ferrari, Department of Biology, California State University, San Bernadino, CA 92407, USA. genes confers resistance to insecticides in populations of Culex quinquefasciatus (Mouchès et al., 1986) and Myzus persicae (Field et al., 1988).

In Culex quinquefasciatus, individuals from an insecticide-resistant strain (Tem-R) carry an estimated 250 times more copies of esterase B1 (Mouchès et al., 1987) and exhibit 120 times higher esterase activity (against $\alpha$-naphthyl acetate substrate) than susceptible individuals; the sex-specific distributions of esterase activities in the resistant strain each span about a twofold range (Ferrari \& Georghiou, 1990).

Several genetic mechanisms can generate copynumber variation in amplified blocks of genes, including gene conversion and unequal recombination between homologous chromosomes or sister chromatids (Fogel et al., 1984, 1988; Petes \& Hill, 1988). These processes have important implications for copynumber changes of amplified genes, both in response to selection and when selection is relaxed. In order to study the forces that influence esterase B1 copynumber change, it is necessary to first assess the existing levels of genetic variation of esterase activity in defined strains and determine the basis of this variation. In the present study, we use a mating design which isolates individual chromosomes that carry amplified esterase B1 genes from the Tem-R strain to determine whether genetic variation of esterase activity has been 
maintained under a long-term programme of insecticidal selection.

\section{Materials and methods}

\section{Mosquito strains}

$S$-Lab. A susceptible laboratory strain lacking highly active esterases, originally collected in 1950 from the San Joaquin Valley of California.

Tem-R. A strain developed from a 1974 field collection from Hanford, CA by selection with the organophosphate insecticide temephos (Ranasinghe \& Georghiou, 1979). All individuals of this strain are homozygous for the highly active B1 esterase allozyme, which shows very high activity against $\alpha$-naphthyl acetate substrate on starch gels. The high activity of the B1 esterase in this strain is due to gene amplification (Mouchès et al., 1986). It is almost certain that this gene amplification was present in some individuals from the original field collection, as the initial assays following laboratory colonization indicated the presence of resistant individuals, and the strain responded rapidly to insecticidal selection in the laboratory. Since its colonization, this strain has been maintained in the laboratory under selection pressure with temephos in each generation at approximately the 30-80 per cent mortality level (about 180 generations).

\section{Backcross families}

An $F_{1}$ generation was produced by crossing about 100 $\mathrm{S}-\mathrm{Lab}$ females to an equal number of Tem-R males. Sixty egg rafts were collected on a single day and hatched together. A sample of 400 first instar larvae was taken from this pool 1 day after hatching and reared in uncrowded conditions on ample amounts of a standard diet.

One hundred and sixty $F_{1}$ females were mated in groups of 10 to single S-Lab males. The females were blood fed and placed individually in $25 \mathrm{ml}$ vials for egg laying. When an egg raft hatched, $30 \mu \mathrm{l}$ of a food suspension, consisting of $1 \mathrm{~g}$ of standard laboratory diet $(3: 1 \mathrm{wt} / \mathrm{wt}$ mixture of finely ground Purina Lab Chow and brewers yeast) per $10 \mathrm{ml}$ of tap water, was added to the vial (day 0). On day 1, 100 larvae from a family were used to establish two replicate groups of 50 larvae each (A and B). These groups were placed in separate plastic rearing cups with $\sim 130 \mathrm{ml}$ of tap water and fed the food suspension on the following schedule (day 1: $0.25 \mathrm{ml}$, day 3-4: $0.375 \mathrm{ml}$; day 5-7: $0.5 \mathrm{ml}$ ). Rearing cups were assigned a position at random in one of two incubators and reared at $27^{\circ} \mathrm{C}$.
All A and B replicates were placed in two respective incubators. Upon emergence, adults were fed a sugar water solution for 3 days and then stored in liquid nitrogen. A total of 58 families (116 replicates) were reared.

\section{Esterase activity measurement}

Previous work demonstrated that the insecticide resistance phenotype segregates as if coded for by a single gene (Pasteur et al., 1980). Thus we expected the amplified esterase genes to segregate as a block in the backcross, giving rise to two classes of individuals; those which carry the amplified block of $\mathrm{B} 1$ genes in the heterozygous condition (BC-RS), and those which do not carry the amplified block of genes (BC-SS). It was necessary to determine whether an individual carried amplified B1 genes prior to assay so that it could be homogenized and diluted to the appropriate level to bring its esterase activity within the linear range of the assay. This was done using a rapid filter paper assay of esterase activity (Pasteur \& Georghiou, 1989). Individuals were ground in homogenization buffer (see below) and $5 \mu \mathrm{l}$ of homogenate spotted onto a strip of filter paper. Filter papers were immersed in a buffer solution containing $\alpha$-naphthyl acetate and then stained in a solution of Fast Garnet. The two classes of backcross offspring were clearly distinguished by the intensity of the stain produced.

Esterase activity was measured according to the methods of O. Dary and G. P. Georghiou (unpublished observations). Individual mosquitoes were homogenized in $100 \mu \mathrm{l}$ of ice-cold $0.1 \mathrm{~m}$ sodium phosphate buffer, pH 6.5, containing 0.5 per cent Triton $\mathrm{X}-100$.

Aliquots of homogenate were diluted with buffer so that esterase activity was within the linear range of resolution of the assay (i.e. between 2 and 20 nmoles $\alpha$-naphthol produced in $30 \mathrm{~min}$ ).

For each individual, $50 \mu \mathrm{l}$ of dilute homogenate were placed in a well of a 96-well microtitre plate held on ice. When all the samples had been loaded the plate was transferred to a water bath at $25^{\circ} \mathrm{C}$ for $10 \mathrm{~min}$. One-hundred microlitres of substrate solution were then added to each well (substrate solution: $0.5 \mathrm{ml}$ $60 \mathrm{~mm} \alpha$-naphthyl acetate in absolute ethanol; $7 \mathrm{ml}$ deionized water; $2.5 \mathrm{ml}$ sodium phosphate buffer (above); $0.01 \mathrm{ml} 2 \mathrm{~mm} \quad 1,5$ bis(4-allyl dimethyl ammonium phenyl) pentan-3-one-dibromide (Wellcome Research Laboratories, Research Triangle Park, $\mathrm{NC}$ ), an acetylcholinesterase inhibitor)].

Plates were incubated for $30 \mathrm{~min}$ at $25^{\circ} \mathrm{C}$. One hundred microlitres of $0.8 \mathrm{mg} / \mathrm{ml}$ Fast Garnet GBC salt (Sigma, St Louis, F-0875) were added to each well, to react with $\alpha$-naphthol, one of the products from the hydrolysis of the substrate, to produce a change in the 
absorbance of the solution. Ten minutes after the Fast Garnet was added the absorbance of each well was measured at $550 \mathrm{~nm}$ using a Bio-Rad model 2550 microtitre plate reader. Absorbance was transformed to nanomoles $\alpha$-naphthol using an $\alpha$-naphthol standard curve.

\section{Protein content determination}

The protein assay was a modification of the Bradford protein microassay (Bradford, 1976). Aliquots of mosquito homogenates (see esterase assay, above) were diluted with deionized water (the presence of Triton $\mathrm{X}-100$ in the homogenization buffer interferes with the protein assay) so that the protein concentration was within the linear range of the assay (2-8 $\mu \mathrm{g}$ protein). Samples were placed in wells of microtitre plates held on ice. The plates were then removed from ice and 200 $\mu \mathrm{l}$ of $1: 4(\mathrm{v}: \mathrm{v})$ solution of Bradford reagent (Bio-Rad, Richmond, CA, 500-0006): deionized water, was added to each well. Plates were held at room temperature for $10 \mathrm{~min}$ with occasional shaking and absorbance measured at $600 \mathrm{~nm}$. Absorbance was transformed to micromoles protein/mosquito using a gamma globulin standard curve.

Three replicate measures of esterase activity and protein content were made for each individual in different microtitre plates.

\section{Experiment 1}

All individuals from both replicates of six backcross families chosen at random were measured for esterase activity and protein content. The replicates of a given family were always run on different days, and all individuals from a replicate were assayed on the same day. One or two of the 12 replicates were processed on any one day. The esterase activity of an individual will depend to some extent on its size. Variation in the mean size of individuals among families could therefore give rise to apparent genetic variation in esterase activity. Protein content was used as a measure of size. The esterase activity of each individual was adjusted by its protein content using the relation:

$$
Y_{\text {adj }}=Y_{\mathrm{i}}-b\left(X_{\mathrm{i}}-X_{*}\right)
$$

Where $Y_{\text {adj }}$ is the adjusted esterase activity of an individual, $Y_{\mathrm{i}}$ is the individual's unadjusted esterase activity, $b$ is the regression coefficient of esterase activity on protein content, $X_{\mathrm{i}}$ is the individual's protein content, and $X_{*}$ is the overall mean protein content of all individuals in all families. The best linear unbiased estimates of regression coefficients were determined by the general linear models procedure (Proc GLM) of the SAS statistical analysis system (SAS Institute, 1985) in the analysis of covariance (ANCOVA) of esterase activity. The ANCOVA model included the effect of family and replicate nested within family, with protein content as a covariate. Proc GLM calculates the regression coefficient from sums of squares and products pooled over all replicates. Separate regression coefficients were calculated for each sex and each genotype (BC-SS, BC$\mathrm{RS})$. An important assumption in adjusting esterase activity by protein content is that the regression coefficient is homogeneous over all families and replicates. This was tested in separate ANCOVAs as the interaction of the covariate (protein content) with each of the effects in the model.

\section{Experiment 2}

The analysis of esterase activity variation among backcross families was designed as a hierarchical analysis of variance. The experimental design is most easily presented by reference to Table 1 . On each assay day $2, F_{1}$ female backcross families from each of two S-Lab males were analysed. To obtain the sample, 12 males from each replicate were examined using the filter paper assay (see above). If less than six males were $\mathrm{BC}$ RS, six additional males were examined. A maximum of six individuals were chosen at random from those identified as BC-RS. If less than six males were BC-RS then all available BC-RS males were used. This resulted in sample sizes of between four and six males per replicate. Each individual was assayed for esterase activity and protein content.

The model for the hierarchical analysis of variance was as follows:

$$
Y_{i j k l m}=u+A_{i}+S_{i j}+F_{i j k}+R_{i j k l}+e_{i j k l m} \text {. }
$$

All effects in the model are nested within all previous effects. To simplify the mathematical description of the model the nesting is not explicitly shown. $Y_{i j k l m}$ is the esterase activity of an individual adjusted by its protein content, $u$ is the overall mean, $A_{i}$ is the effect of the $i$ th assay day $(i=1 \ldots 8), S_{i j}$ is the effect of the $j$ th $\mathrm{S}$-Lab male $(j=1 \ldots 2), F_{i j k}$ is the effect of the $k$ th $\mathrm{F}_{1}$ female $(k=1 \ldots 2), R_{i j k l}$ is the effect of the $l$ th replicate $(l=1 \ldots 2)$, and $e_{i j k l m}$ is the within replicate error effect $(m=1 \ldots 4-6)$. All effects are considered random. All analyses were run using the GLM procedure of the SAS statistical analysis system (SAS Institute, 1985). Esterase activities were adjusted by protein content prior to analysis as described above except that the best linear unbiased estimate of $b$ was determined by the SAS GLM procedure in the analysis of covariance formed by introducing protein content as a covariate into the analysis of variance model shown above. $F$ tests and variance components were calculated from 
Table 1 Mean adjusted esterase activities (nmoles $\alpha$-naphthyl acetate hydrolyzed per minute per microgram mosquito protein) of $\mathrm{BC}-\mathrm{RS}$ males of replicate $\mathrm{F}_{1}$ female family groups nested within S-Lab male and day of assay

\begin{tabular}{|c|c|c|c|c|c|c|}
\hline Day & $\begin{array}{l}\text { S-Lab } \\
\text { male }\end{array}$ & $\begin{array}{l}F_{1} \\
\text { female }\end{array}$ & Rep & $N$ & $\bar{X}$ & S.E. \\
\hline \multirow[t]{8}{*}{1} & \multirow[t]{4}{*}{$M$} & \multirow[t]{2}{*}{ M2 } & A & 6 & 2.10 & 0.13 \\
\hline & & & B & 6 & 2.16 & 0.07 \\
\hline & & \multirow[t]{2}{*}{ M3 } & A & 6 & 2.34 & 0.15 \\
\hline & & & B & 5 & 2.37 & 0.14 \\
\hline & \multirow[t]{4}{*}{$\mathrm{N}$} & \multirow[t]{2}{*}{$\mathrm{N} 2$} & A & 6 & 1.95 & 0.11 \\
\hline & & & B & 6 & 1.67 & 0.18 \\
\hline & & \multirow[t]{2}{*}{ N9 } & A & 6 & 2.41 & 0.08 \\
\hline & & & B & 6 & 2.06 & 0.10 \\
\hline \multirow[t]{8}{*}{2} & \multirow[t]{4}{*}{$\mathrm{H}$} & \multirow[t]{2}{*}{ H1 } & A & 6 & 2.30 & 0.13 \\
\hline & & & B & 5 & 2.09 & 0.25 \\
\hline & & \multirow[t]{2}{*}{$\mathrm{H} 3$} & A & 6 & 2.21 & 0.15 \\
\hline & & & $\mathrm{B}$ & 6 & 1.97 & 0.08 \\
\hline & \multirow[t]{4}{*}{$\mathrm{N}$} & \multirow[t]{2}{*}{ N1 } & A & 6 & 2.47 & 0.14 \\
\hline & & & B & 5 & 2.40 & 0.23 \\
\hline & & \multirow[t]{2}{*}{ N4 } & A & 6 & 1.68 & 0.08 \\
\hline & & & B & 6 & 1.47 & 0.07 \\
\hline \multirow[t]{8}{*}{3} & \multirow[t]{4}{*}{ A } & \multirow[t]{2}{*}{ A1 } & A & 4 & 2.11 & 0.07 \\
\hline & & & B & 5 & 1.89 & 0.20 \\
\hline & & \multirow{2}{*}{ A6 } & A & 6 & 1.83 & 0.09 \\
\hline & & & B & 6 & 1.70 & 0.09 \\
\hline & \multirow[t]{4}{*}{$\mathrm{J}$} & \multirow[t]{2}{*}{$\mathrm{J} 2$} & A & 6 & 2.30 & 0.14 \\
\hline & & & B & 6 & 2.23 & 0.08 \\
\hline & & $\mathrm{J} 4$ & A & 6 & 1.89 & 0.13 \\
\hline & & & B & 5 & 1.54 & 0.11 \\
\hline 4 & $\mathrm{E}$ & E2 & A & 5 & 1.97 & 0.15 \\
\hline & & & B & 6 & 1.92 & 0.18 \\
\hline & & E6 & A & 6 & 1.87 & 0.13 \\
\hline & & & B & 6 & 2.00 & 0.16 \\
\hline & 1 & 13 & A & 6 & 2.39 & 0.11 \\
\hline & & & B & 5 & 1.76 & 0.08 \\
\hline & & I8 & A & 6 & 2.15 & 0.16 \\
\hline & & & B & 6 & 2.02 & 0.14 \\
\hline 5 & D & D2 & $\mathrm{A}$ & 6 & 1.80 & 0.11 \\
\hline & & & B & 6 & 1.26 & 0.03 \\
\hline & & D4 & A & 6 & 1.67 & 0.07 \\
\hline & & & B & 6 & 1.33 & 0.07 \\
\hline & F & $\mathrm{F} 2$ & A & 6 & 1.73 & 0.09 \\
\hline & & & B & 6 & 1.97 & 0.16 \\
\hline & & F9 & A & 5 & 1.34 & 0.07 \\
\hline & & & B & 6 & 1.67 & 0.15 \\
\hline 6 & $\mathrm{G}$ & $\mathrm{G} 2$ & A & 6 & 2.09 & 0.08 \\
\hline & & & B & 6 & 1.92 & 0.02 \\
\hline & & G8 & A & 5 & 2.64 & 0.17 \\
\hline & & & B & 6 & 3.03 & 0.26 \\
\hline & $\mathrm{L}$ & L1 & A & 6 & 1.47 & 0.07 \\
\hline & & & B & 6 & 1.40 & 0.09 \\
\hline & & L5 & A & 5 & 1.47 & 0.14 \\
\hline & & & B & 6 & 1.57 & 0.08 \\
\hline 7 & B & B1 & A & 6 & 1.82 & 0.15 \\
\hline & & & B & 5 & 1.67 & 0.14 \\
\hline
\end{tabular}

Table 1. Continued.

\begin{tabular}{|c|c|c|c|c|c|c|}
\hline Day & $\begin{array}{l}\text { S-Lab } \\
\text { male }\end{array}$ & $\begin{array}{l}F_{1} \\
\text { female }\end{array}$ & Rep & $N$ & $\bar{X}$ & S.E. \\
\hline \multirow{14}{*}{8} & \multirow{6}{*}{ C } & \multirow[t]{2}{*}{ B8 } & A & 6 & 1.46 & 0.11 \\
\hline & & & B & 5 & 1.53 & 0.11 \\
\hline & & \multirow[t]{2}{*}{$\mathrm{C} 3$} & A & 6 & 1.66 & 0.14 \\
\hline & & & B & 6 & 1.61 & 0.06 \\
\hline & & \multirow[t]{2}{*}{ C7 } & A & 6 & 2.09 & 0.08 \\
\hline & & & B & 6 & 2.27 & 0.19 \\
\hline & \multirow[t]{4}{*}{$\mathrm{M}$} & \multirow[t]{2}{*}{ M10 } & A & 5 & 1.76 & 0.16 \\
\hline & & & B & 6 & 1.97 & 0.08 \\
\hline & & \multirow[t]{2}{*}{ M7 } & A & 6 & 2.07 & 0.11 \\
\hline & & & B & 4 & 2.05 & 0.11 \\
\hline & \multirow[t]{4}{*}{0} & \multirow[t]{2}{*}{ O5 } & A & 6 & 2.09 & 0.14 \\
\hline & & & B & 6 & 1.93 & 0.10 \\
\hline & & \multirow[t]{2}{*}{ O7 } & A & 6 & 1.95 & 0.14 \\
\hline & & & B & 6 & 1.67 & 0.10 \\
\hline
\end{tabular}

expected mean squares as outlined by Sokal \& Rohlf (1969). In both experiments esterase activity was represented as nanomoles $\alpha$-naphthyl acetate substrate hydrolyzed per minute per microgram of mosquito protein by dividing the adjusted activity as defined above by the overall mean protein content of all individuals in the group.

\section{Results}

\section{Experiment 1}

The purpose of this experiment was to test the predictions that the amplified esterase genes would segregate as a block in the backcross, and that copy-number variants would not be produced at high frequency. This was necessary to insure that BC-RS full-siblings would be likely to receive the same number of copies of esterase B1. Generation of copy-number variants at high frequency would inflate the error variance of esterase activity.

The regression coefficients of esterase activity on protein content were significant for each genotypic class and sex $(P<0.0001$ in all cases). The homogeneity of each regression coefficient over families and replicates was tested in separate ANCOVAs as the interaction effect of the covariate (protein content) with each of these effects. Neither interaction was significant in any of the four analyses.

The mean survival among backcross families was 91 per cent. Of the 543 individuals examined in the filter paper esterase assay, 50.6 were classified as BC-RS, carrying amplified esterase genes, and 49.4 were BC- 
SS. The distributions of protein-adjusted esterase activities of males and females, pooled over replicates and families, are shown in Fig. 1. Note that the BC-SS and BC-RS genotypic classes are plotted on different scales. The scale intervals were chosen to represent approximately the same proportion of the mean of each class. The esterase activities of males fell into two distinct classes (Fig. 1). Most females also fell within two distinct esterase activity classes, however one female, classified as BC-SS by filter-paper assay, exhibited a relatively high esterase activity for a BC-SS individual (Fig. 1). The activity was confirmed in a second assay from the original homogenate. This individual may have inherited a chromosome carrying an intermediate number of copies of esterase B1, produced by unequal recombination or gene conversion in an $F_{1}$ female.

\section{Experiment 2}

Pooled over the 64 replicates, the proportion of males classified as BC-RS by the filter paper assay was 0.52 , not significantly different from the expected 0.50 $(\chi$-square $=1.51, P=0.22,1 \mathrm{df})$. The proportion of $\mathrm{BC}$-RS individuals among the first 12 males in a family examined by the filter-paper assay ranged from 0.29 to 0.71 . Chi-square analysis found no significantly heterogeneity in this value among families (heterogeneity $\chi$-square $=41.3, P=0.10,31 \mathrm{df}$ ).

There was a highly significant regression of esterase activity on protein content $(b=1.676$, S.E. $=0.213$,
$F=62.1,1,301 \mathrm{df}, P<0.0001)$. The homogeneity of this regression was tested in a separate ANCOVA as the interaction of the covariate (protein content) with each of the effects shown in the hierarchical analysis of variance (see Table 2 ). No significant interactions were observed.

Replicate mean esterase activities ranged from 1.26 to 3.03 , while $F_{1}$ female family means ranged from 1.43 to 2.85 (Table 1). Analysis of variance (Table 2) indicated that neither the day of assay nor the S-Lab male had a significant effect on esterase activity variation among the backcross families. $F_{1}$ female effects and replicate effects were highly significant sources of variation. Variance components (Table 2) estimated that between replicate variance accounted for about 6.3 per cent of the variance of esterase activity. Variation attributable to $F_{1}$ female effects, a measure of genetic variation, accounted for 31.6 per cent of the variance in esterase activity. When the non-significant day and S-Lab male effects were eliminated from the model, $F_{1}$ female effects accounted for about 43 per cent of the variance in esterase activity.

A comparison of mean esterase activities of replicates within families found that in most cases $(21 / 32)$ the A replicate had a higher mean esterase activity than the B replicate. This suggested an 'incubator effect' on esterase activity. While the effect on the average esterase activity of all families was small (1.97 in A replicates vs. 1.88 in $B$ replicates), the difference could potentially have resulted in an inflated estimate of between replicate variance in the analysis reported
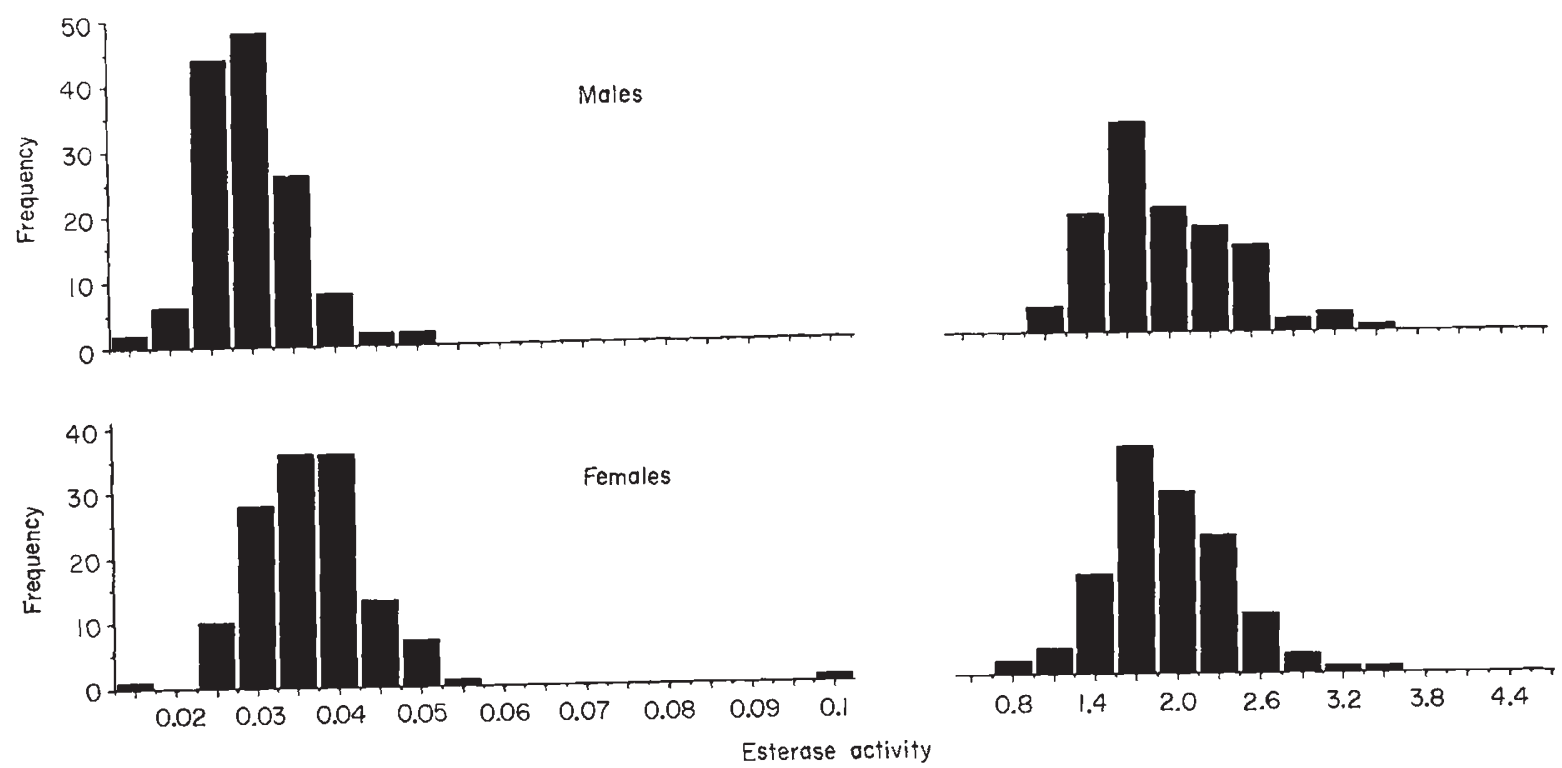

Fig. 1 Frequency distributions of adjusted esterase activities (nanomoles $\alpha$-napthyl acetate hydrolyzed per minute per microgram protein) of backcross males and females. 
Table 2 Nested analysis of variance of esterase activity and variance components associated with sources of variances

\begin{tabular}{lrlllr}
\hline Source & df & $\begin{array}{l}\text { Mean } \\
\text { square }\end{array}$ & $F$ & \multicolumn{1}{l}{$\begin{array}{l}\text { Variance } \\
\text { component* }\end{array}$} & Percentage \\
\hline Day & 7 & 1.320560 & $0.83 \mathrm{~ns}$ & -0.003751 & $(0.0)$ \\
S-Lab male & 8 & 1.589071 & $1.73 \mathrm{~ns}$ & 0.024801 & $(12.2)$ \\
F $_{1}$ female & 16 & 0.919549 & $5.27^{* * *}$ & 0.065249 & $(32.2)$ \\
Replicate & 32 & 0.174598 & $1.76^{* *}$ & 0.013203 & $(6.5)$ \\
$\begin{array}{l}\text { Within replicate } \\
\quad \text { (error) }\end{array}$ & 301 & 0.099441 & & 0.099441 & $(49.1)$ \\
\hline
\end{tabular}

*Variance components were calculated using expected mean squares. $F$ values were calculated from the observed mean squares and tested using the degrees of freedom shown. Satterthwaite's approximation for unequal sample sizes (Sokal \& Rohlf, 1969 , p. 280) had very little effect on $F$ values.

ns $=F$ not significant at $P<0.05$.

** $F$ significant at $P<0.01$.

*** $F$ significant at $P<0.0001$.

above. We found a significant $F_{1}$ female effect in our analysis, in spite of this potential bias. We assessed the influence of removing the incubator effect on the components of variance by equalizing the overall mean esterase activities of the A and B replicates. Half the difference between overall replicate means was subtracted from each observation in A replicates and added to each observation in B replicates, and the data were reanalysed as above. There was little effect on the estimates of the percentage of the variance in esterase activity attributable to each effect, and there was no change in the significance levels reported above.

\section{Discussion}

The relative proportions and distribution of BC-RS and BC-SS individuals in experiment 1 indicates that the amplified esterase B1 genes segregate as a block and suggests that copy-number variants within the region of amplification are generated at low frequency in $F_{1}$ females. While genetic processes could have generated copy-number variants which still fell within the BC-RS range of esterase activity, this seems unlikely. A substantial frequency of such events would have resulted in an excess of BC-RS individuals among the backcross offspring, which was not observed in either experiment.

Given these results, we can be reasonably confident that BC-RS full-siblings all receive the same number of copies of esterase B1. Fournier et al. (1987) found that esterase B1 consists of only one detectable molecular form in the Tem- $R$ strain, making hidden allelic variation within or between amplified blocks of genes unlikely. The S-Lab male parents of the backcross families contribute a normal complement of esterases to their offspring, but the esterase activity of the BC-RS males is predominantly due to the amplified B1 esterase. In experiment $1 \mathrm{BC}-\mathrm{RS}$ males exhibited about 65 times the esterase activity of BC-SS males. No active esterases other than esterase $\mathrm{B} 1$ have been observed in the Tem- $\mathrm{R}$ strain. No esterase polymorphism has been observed within either strain.

Given these results, the significant variance component attributable to $F_{1}$ females is due either to copynumber variation of the esterase $\mathrm{B} 1$ gene among the Tem-R chromosomes they carry, effects due to specific polymorphic modifiers of esterase activity segregating in the Tem- $R$ strain and transmitted differentially to $F_{1}$ females, or non-specific effects on esterase activity due to variation in genetic background.

The S-Lab strain has been in laboratory culture for 39 years and is highly inbred. The lack of an S-Lab male effect in experiment 2 suggests that the genetic background provided by S-Lab males is homogeneous across families and does not contribute to esterase activity variation among $\mathrm{BC}-\mathrm{RS}$ males.

The Tem-R strain has been subjected to insecticidal selection at the 30-80 per cent mortality level for more than 180 generations of laboratory culture. Using records of the number of larvae subjected to selection each generation, and making reasonable assumptions about the number of females potentially contributing to this larval pool, the effective population size of the Tem-R strain has probably been between 60 and 120 . In 180 generations, this would produce an inbreeding coefficient of between 0.53 and 0.78 from drift alone 
(Hartl \& Clark 1989). This, coupled with the strong selection for high esterase activity imposed each generation makes it unlikely that many major modifiers of esterase activity are still polymorphic in the Tem-R strain.

If a major modifier of esterase activity was polymorphic in Tem- $\mathrm{R}$ it might be detectable in backcross progeny from its effect on the distribution of esterase activities. A major modifier gene would probably produce a discontinuity in the distribution of esterase activities within the BC-RS progeny class. No such discontinuity was observed in experiment 1 (Fig. 1). A polymorphic modifier distributed among the backcross families might give rise to heterogeneity of within family variance because it would tend to inflate the variance of esterase activity in families in which it was assorting. This was investigated using Bartlett's test of homogeneity of variance (Sokal \& Rohlf, 1969). Family variance was calculated for the 32 families used in experiment 2 as the pooled variance of the two replicates weighted by their sample sizes. Log transformed esterase activities were used as there was a significant correlation between family mean and variance for untransformed esterase activities. No significant heterogeneity of variance was detected among families $\left(\chi^{2}=32.4,31 \mathrm{df}, P>0.25\right)$.

This analysis suggests that the genetic variance in esterase activity attributed to $F_{1}$ females is not due to one or two modifiers of strong effect. As the number of modifiers in our model increases, our ability to detect them using the above methods decreases. At the same time, however, the relative importance of such modifiers in producing between-family variance also decreases, as the larger the modifier pool, the higher the probability that families would receive combinations of similar effect. In addition, and perhaps more importantly, the backcross design insures that the assortment of Tem-R modifier genes would contribute substantially to within-family variance, thereby reducing their contribution to estimates of between-family variance.

Thus, while modifier genes are a potential source of genetic variance of esterase activity, their contribution to between-family variance is probably minor. The most likely source of $F_{1}$ female variance of esterase activity is esterase B1 copy-number variation among the sample of Tem- $\mathrm{R}$ chromosomes which were isolated in $F_{1}$ females. In yeast, a variety of meiotic processes can result in the generation of copy-number variants for duplicated or more highly amplified genetic elements. These include unequal reciprocal recombination between homologues or sister-chromatids, as well as inter- and intrachromosomal gene-conversion (Fogel et al., 1984, 1988; Jackson \& Fink, 1985).
These processes can occur at fairly high frequency (10-20 per cent of tetrads). In our experiment it appears that B1 copy-number variants arise at low frequency (less than 1 in 500 gametes) in $F_{1}$ individuals that carry the amplified block on only one homologue. The rate of occurrence of copy-number variants in the Tem-R strain, in which both homologues carry amplified genes, is unknown, but might be expected to be somewhat higher than we observed, given that homology in the region of amplification would be greater.

It appears that the observed level of esterase activity variation in the Tem- $R$ strain is being maintained by a balance between the generation of new copy-number variants by genetic processes and the elimination of variation at the low end of the esterase activity distribution by insecticidal selection. While the Tem-R strain has been subjected to fairly strong selection since 1978 , over the past several years there has not been a noticeable change in the level of resistance of the strain. A limit on copy-number increase may be imposed by a negative relation between copy-number and fitness, especially at the high end of the copy-number distribution. Such a relation has been observed in cell culture (Schimke, 1982, 1986). Only rarely have we observed field-collected individuals with esterase activities comparable to those observed in Tem-R individuals (G. P. Georghiou, unpublished observations). This could be due to a weaker selection in field populations than in the laboratory; or may indicate that this level of amplification has a detrimental effect on fitness in the field.

For tandemly repeated genes which segregate as a block, quantitative genetic variation due to copynumber differences is analogous to variation caused by allelic differences at a locus. Each copy-number class defines a different 'allele'. The range of esterase activities among all BC-RS males was about 5.5-fold, with an approximate two-fold range in $\mathrm{F}_{1}$ family means. Field populations of Culex quinquefasciatus can exhibit much wider ranges of esterase activity, up to 120 -fold in mixed populations of insecticide-resistant and susceptible individuals (G. P. Georghiou, unpublished observations). The distributions appear continuous, which suggests that a large number of esterase B1 copy-number classes and/or modifier genes contribute to the variation. The extensive variation in activity associated with esterase $\mathrm{B} 1$, and the fact that this variation is affected by a known selective force, insecticide treatment, makes it a potentially valuable model system for studying how genetic systems respond to selection for increased enzyme activity or amount.

A better understanding of the forces influencing esterase B1 activity and copy-number variation in populations will require more information about the 
frequency and degree to which meiotic processes generate esterase B1 copy-number variation, and the forces which act on this variation. Among the more important factors which will influence copy-number change are the relationships between esterase activity and copy-number, esterase activity and the probability of surviving insecticide treatment, and esterase activity and reproductive fitness.

\section{Acknowledgements}

We would like to thank E. Parsons and M. Wirth for technical assistance, and Drs L. P. Nunney, C. E. Taylor, C. A. Sassaman and an anonymous reviewer for their comments on the original manuscript. This research was supported in part by US Army Medical Research Acquisition Activity Contract No. DAM1785-C-5170 (to GPG), grants from the National Science Foundation (INT-8715230) and the Centre National de la Recherche Scientifique under the US-France Collaborative Science Program, and by the University of California Mosquito Research Program.

\section{References}

BRADFORD, M. M. 1976. A rapid sensitive method for the quantitation of microgram quantities of protein utilizing the principle of protein-dye binding. Anal. Biochem., 72 , 255-260.

FERRARI, J. A. AND GEORGHIOU, G. P. 1990. Esterase B1 activity variation within and among insecticide resistant, susceptible and heterozygous strains of Culex quinquefasciatus. J. Econ. Entomol. (in press).

FOURNIER, D., BRIDE, J.-M., MOUCHĖs, C. et al., 1987. Biochemical characterization of esterases A1 and B1 associated with organophosphate resistance in the Culex pipiens $\mathrm{L}$. complex. Pestic. Biochem. Physiol., 27, 211-217.

FIELD, L. M., DEVONSHIRE, A. L. AND FORDE, B. G. 1988. Molecular evidence that insecticide resistance in peach-potato aphids (Myzus persicae Sulz.) results from amplification of an esterase gene. Biochem. J., 251, 309-312.

FOGEL, S. AND WELCH, J. w. 1982. Tandem gene amplification mediates copper resistance in yeast. Proc. Nat. Acad. Sci. USA, 79, 5342-5346.

FOGEL, S., WELCH, J. W., CATHALA, G. AND KARIN, M. 1983. Gene amplification in yeast: CUP1 copy number regulates copper resistance. Current Genetics, 7, 347-355.

FOGEL, S., WELCH, J. W. AND LOUIS, E. J. 1984. Meiotic gene conversion mediates gene amplification in yeast. Cold Spring Harbor Symp. Quant. Biol., 49, 55-65.

FOGEL, S., WELCH, J. W. AND MALONEY, D. H. 1988. The molecular genetics of copper resistance in Saccharomyces cerevisiae
- a paradigm for non-conventional yeasts. J. Basic Microbiol., 28, 147-160.

HARTL, D. L. AND ClARK, A. G. 1989. Principles of Population Genetics, 2nd edn, Sinauer Associates, Sunderland, MA.

JACKSON, J. A. AND FINK, G. R. 1985. Meiotic recombination between duplicated genetic elements in Saccharomyces cerevisiae. Genetics, 109, 303-332.

LAURIE-AHLBERG, C. C., MARONI, G., BEWLEY, G. C., LUCCHESI, J. C. AND WEIR, B. S.. 1980. Quantitative genetic variation of enzyme activities in natural populations of Drosophila melanogaster. Proc. Nat. Acad. Sci. USA, 77, 1073-1077.

LAURIE-AHLBERG, C. C., WILTON, A. N., CURTSINGER, J. W. AND EMIGH, T. H. 1982. Naturally occurring enzyme activity variation in Drosophila melanogaster. I. Sources of variation for 23 enzymes. Genetics, 102, 191-206.

MARONI, G., WISE, J., YOUNG, J. E. AND OTTO, E. 1987. Metallothionein gene duplications and metal tolerance in natural populations of Drosophila melanogaster. Genetics, 117, 739-744.

MOUCHÈs, C., PASTEUR, N., BERGÉ, J. et al. 1986. Amplification of an esterase gene is responsible for insecticide resistance in a California Culex mosquito. Science, 233, 778-780.

MOUCHÈs, C., MAGNIN, M., BERGÉ, J.-B. et al. 1987. Overproduction of detoxifying esterases in organophosphate-resistant Culex mosquitoes and their presence in other insects. Proc. Nat. Acad. Sci. USA, 84, 2113-2116.

PASTEUR, N. AND GEORGHIOU, G. P. 1989. Improved filter paper test for detecting and quantifying esterase activity in organophosphate-resistant mosquitoes (Diptera: Culicidae). J. Econ. Entomol., 82, 347-353.

PASTEUR, N., GEORGHIOU, G. P. AND RANASINGHE, L. E. 1980. Variations in degree of homozygous resistance to organophosphorous insecticides in Culex quinquefasciatus Say. Proc. Calif. Mosq. Vector Cont. Assoc., 48, 69-73.

PETES, T. D. AND HILL, C. W. 1988. Recombination between repeated genes in microorganisms. Ann. Rev. Genet., 22, 147-168.

RANASINGHE, L. E. AND GEORGHIOU, G. P. 1979. Comparative modification of insecticide-resistance spectrum of Culex pipiens fatigans Wied. by selection with temephos/ synergist combinations. Pesticide Sci., 10, 502-508.

SAS INSTITUTE. 1985. SAS User's Guide: Statistics. Version 5 Edition. Cary, N.C.

SCHIMKE, R. T. 1982. Studies on gene duplications and amplifications - An historical perspective. In: Gene Amplification, Schimke, R. T. (ed.), Cold Spring Harbor Laboratory, pp. 1-6.

SCHIMKE, R. T. 1986. Methotrexate resistance and gene amplification, mechanisms and implications. Cancer, 57, 1912-1917.

SOKAL, R. K. AND ROHLF, F. J. 1969. Biometry, W. H. Freeman, San Francisco.

STARK, G. R. AND WAHL, G. M. 1984. Gene amplification. Ann. Rev. Biochem., 53, 447-491. 